\title{
Nowy słownik języka krymskokaraimskiego Gulayhan Aqtay i Henryka Jankowskiego (2015) z dyskusją nad odrębnością tego języka w klasyfikacji języków w tle
}

\author{
Michał Németh \\ Uniwersytet Jagielloński, Wydział Filologiczny \\ Instytut Językoznawstwa
}

\begin{abstract}
The New Crimean Karaim Dictionary of Gulayhan Aqtay and Henryk Jankowski (2015) and the Discussion Concerning the Position of This Language in the Classification of the Turkic Languages
\end{abstract}

Summary: This short review-article contains a number of observations regarding the new Crimean Karaim-English dictionary authored by Aqtay and Jankowski (2015) and the state of Crimean Karaim lexicography, as well as remarks on the discussion of the position of Crimean Karaim in the classification of Turkic languages.

Keywords: Crimean (Eastern) Karaim, Karaim lexicography, the relation of Eastern and Western Karaim

I. Turkolog poświęcający się lekturze tekstów krymskokaraimskich mógł dotychczas skorzystać z kilku słowników tego języka. Zacząć trzeba od tego, że od 1974 roku miał do dyspozycji wydany w Moskwie trójjęzyczny słownik karaimsko-rosyjsko-polski (często skracany jako KRPS lub KarRPS, zob. Baskakov, N. A. i in. (red.)), w którym zawarto słownictwo dialektu północno-zachodniego, dialektu południowo-zachodniego i dialektu wschodniego (lub: 
krymskiego). Był on, i jest nadal, podstawowym narzędziem pracy dla badaczy zajmujących się tym językiem. Mimo swych zalet, jak np. dobra redakcja hasel, użycie kwalifikatorów etymologicznych czy podawanie źródła występowania danego wyrazu, nie jest on, jak każde dzieło, pozbawiony błędów, o czym środowisko turkologów wiedziało od dawna. Rzecz w tym, że na podstawie tego właśnie słownika $\mathrm{z}$ biegiem lat powstało szereg innych - w tym również słowników wschodniokaraimskich - czy to w wyniku ekscerpcji danych krymskich i nieznaczne uzupełnienie ich o dalszy materiał, czy to poprzez „obracanie” go na słownik rosyjsko-karaimski lub turecko-karaimski ${ }^{1}$, a ich autorzy nie zawsze przejmowali dane językowe zawarte w KRPS bezkrytycznie ${ }^{2}$. Dlatego też do niektórych słowników dialektu krymskiego należy podejść z pewną dozą ostrożności, bowiem autorzy niektórych z nich to osoby znające dobrze język karaimski, ale będące bez przygotowania leksykograficznego. Wcześniej, bo w 1970 roku powstał w Symferopolu słownik Zacharija Sinaniego, jednak aż do 2007 roku pozostał on w formie maszynopisu (autor zmarł w 1970 roku), nie miał on szerokiego zasięgu w literaturze fachowej, a autorzy KRPS nie uwzględnili go w swojej pracy.

Najważniejszą zaletą opublikowanego w 2015 roku słownika krymskokaraimskiego autorstwa Gulayhan Aqtay oraz Henryka Jankowskiego jest to, że jest on oparty w dużej mierze na materiałach źródłowych, a materiał językowy przejęty z istniejących słowników został poddany analizie krytycznej. Co więcej, we wstępie przeczytamy rzetelną recenzję wykorzystanych źródeł (w tym również słowników) z pełnym omówieniem problemu związanego z interpretacją językową zebranego w nich materiału. To ważne, bo w przypadku języka wymarłego nie ma możliwości potwierdzenia znaczenia czy zakresu użycia danego wyrazu drogą ankietowania.

Autorzy zrewidowali najważniejsze źródła krymskokaraimskie użyte dla potrzeb KRPS, w tym przede wszystkim materiał zebrany przez Seraję Szapszała (w słowniku oznaczony kwalifikatorem Ш; jest to ok. 5 tys. haseł $)^{3}$, materiał z tzw. rękopisu paryskiego (rkp. przechowywany w Bibliothèque nationale de

1 Zob. np. słowniki Marka Chafuza (1995), Borisa Leviego (2005; pierwsze wyd. 1996), Tülay Çulhy (2006) oraz Marka Lavrinovicza (2007, 2012).

2 Słownik KRPS posłużył jako baza materiałowa również dla dwóch słowników dialektu północno-zachodniego: chodzi o słownik Józefowicza (2008) i Juchniewicza (2008).

3 Materiał ten został wstępnie oceniony również w zeszłorocznym artykule Jankowskiego (2014: 55-57) opublikowanym w Almanachu Karaimskim. 
France, sygantura Hebr. 666), materiał z XVII-wiecznego dzieła pt. Zecher rav ${ }^{4}$ oraz materiał zebrany w słowniku Wilhelma Radloffa (1893-1911). O materiale tym się okazało, że choć jest w dużej mierze wiarygodny, to jednak nie jest pozbawiony błędów czy niejasności. W nowym słowniku poprawione zostały przede wszystkim błędne transkrycpje czy błędnie przypisane znaczenia, a w przypadkach, gdy autorom nie udało się dotrzeć do źródeł i cytują dane za istniejącymi słownikami (przede wszystkim za KRPS), sygnalizują to znakiem zapytania, by użytkownik słownika krymskokaraimsko-angielskiego mógł wziąć to pod uwagę w swej pracy.

2. Słownik ten powstaje w czasie, gdy coraz częściej kwestionuje się tradycyjny pogląd dotyczący praojczyzny Karaimów i statusu języka wschodniokaraimskiego w klasyfikacji języków turkijskich. Według akceptowanego w szerokich kręgach historyków i językoznawców poglądu praojczyzną Karaimów był Krym, gdzie przyjęli oni swoją religię i skąd ruszyły ich fale osadnicze na zachód, a pozostali na Krymie Karaimi to przodkowie żyjących tam jeszcze do niedawna Karaimów krymskich. Coraz częściej pojawiają się jednak teorie kwestionujące te założenia. Według tej najszerzej dyskutowanej, głoszonej dziś między innymi przez Dana Shapirę (2003: 661-662, 669, 2013: 157), Karaimi mieli przybyć do Galicji i na Litwę z terenów Złotej Ordy (bez bliższego sprecyzowania geograficznego; notabene Złota Orda obejmowała również Krym) i już przed ich przybyciem na owe tereny mówili różnymi dialektami ${ }^{5}$. Według tej teorii gminy Karaimów na Krymie zostały założone przez Karaimów migrujących z terenów I Rzeczpospolitej, znacznie później niż dotychczas sądzono. Istotną konsekwencją takiego ujęcia zdarzeń jest natomiast negowanie istnienia osobnego dialektu krymskokaraimskiego. Postrzegany jest on według popierających tę teorię jako sztucznie utworzony język, ulepiony dla potrzeb tłumaczeń

4 Dzieło opublikowane w Ortaköy (de facto Konstantynopol), zob. poz. 7763-7764 w bibliografii Walfisha (2011: 675-767).

5 Ten ostatni pogląd o rozbiciu dialektalnym języka karaimskiego jeszcze przed wywędrowaniem z terenów praojczyzny podzielało kilku badaczy, w tym Radloff (1888: 173-182), Tadeusz Kowalski (1929: xlviii-xlix), czy Aleksander Dubiński (1968: 215; 1993: 37-42). Najnowsze badania filologiczne najstarszych znanych rękopisów świadczą raczej o tym, że podział dialektalny jako taki prawdopodobnie nie istnial (nie wliczając drobnych różnic). Jednak kwestia ta jest daleka od końcowego rozstrzygnięcia. Zob. przede wszystkim artykuł Michała Németha (2015a). 
biblijnych na bazie języka zachodniokaraimskiego w wyniku zmieszania go z językiem Tatarów krymskich ${ }^{6}$.

Teoria ta wciąż czeka na należyte udokumentowanie od strony historycznej i filologiczno-językoznawczej. W świetle licznych źródeł wschodniokaraimskich (rękopiśmiennych i drukowanych) negowanie istnienia tego języka jest bezpodstawne - niezależnie od tego czy to język sztucznie utworzony czy nie. Można i z całą pewnością należy badać procesy powstania krymskokaraimskich zabytków językowych (a w szczególności tłumaczeń biblijnych), należy również zbadać jego relację do dialektów zachodnich lub do języka Tatarów krymskich ${ }^{7}$, jednak trudno negować istnienie czegoś, co istnieje - nawet gdyby zostało udowodnione, że język Karaimów krymskich był językiem sztucznym. Język esperanto też jest językiem sztucznym a przecież nikt nie kwestionuje faktu istnienia czy sensu pisania słowników tego języka, argumentując, że jest tworem powstałym na bazie języków romańskich, germańskich czy słowiańskich.

Nie można też całkiem bagatelizować wątliwości zgłaszanych przez Shapirę czy innych badaczy. Analizy języka przekładów biblijnych na język wschodniokaraimski wykazują szereg powiązań z tłumaczeniami na język zachodniokaraimski ${ }^{8}$. Wyrażono tam między innymi podejrzenie, że tłumaczenia krymskie mogły powstawać (lub powstawały; stopień kategoryczności tych sformułowań jest różny) na bazie już istniejących tłumaczeń północno- lub południowo-zachodnich. Jest to wysoce prawdopodobne choćby z tego względu, że trudno sobie wyobrazić tłumacza tekstów biblijnych niezaznajomionego z wcześniejszymi przekładami - tym bardziej, że to przecież zwykle duchowni na co dzień korzystający z Biblii i przekładów biblijnych podejmowali się takiej pracy. Jednak

6 Zob. przede wszystkim artykuł Shapiry (2013: 178), gdzie polemizuje on głównie z Henrykiem Jankowskim (więcej o tym niżej).

7 W istocie wpływ krymskotatarskiego (a także krymskoosmańskiego) na język Karaimów krymskich był na tyle silny, że już w XX wieku głoszono pogląd, że ich język nie był dialektem karaimskim, ale odmianą właśnie krymskotatarskiego. Jednak nawet jeśli stopień asymilacji językowej Karaimów w XIX w. był znaczący, to świadectwo starszych zabytków językowych wyraźnie wskazuje na silne powiązania dialektu wschodniego z dialektami zachodnimi. Najbardziej szczegółowe badania na temat odrębności języka wschodniokaraimskiego prowadził Henryk Jankowski, współautor omawianego słownika, zob. H. Jankowski (2003a, 2003b, 2008). O statusie języka wschodniokaraimskiego jako osobnego dialektu pisał także Aleksander Dubiński (1993).

8 O tym zob. przede wszystkim prace Jankowskiego (1997, 2009, 2015), Shapiry (2013) czy Németha (2015b). 
nawet jeśli udowodnimy drugą żmudnych badań kolacjonowania tłumaczeń poszczególnych ksiąg Starego Testamentu, że krymskokaraimskie przekłady biblijne powstawały na bazie tych zachodniokaraimskich, to taki wynik badań w żadnym wypadku nie może być dowodem nieistnienia odrębnego dialektu wschodniokaraimskiego. Nie można przecież utożsamiać liturgicznego języka pisanego z językiem mówionym?

Powiązania językowe między wschodnio- i zachodniokaraimskimi przekładami biblijnymi, które wynikają ze wstępnych prób afiliacji tych tekstów (zob. przypis 8) każą nam jednak zastanowić się, czy tej części słownictwa użytego w tłumaczeniach krymskich, która nie była charakterystyczna dla języków turkijskich Krymu, a była znana z dialektów zachodniokaraimskich, nie należałoby traktować raczej jako zapożyczenia interdialektalne. Jednak udzielenie odpowiedzi na to pytanie jest za każdym razem niezwykle trudne. Po pierwsze w przypadku wyrazów rodzimych niełatwe czy wręcz niemożliwym jest odróżnić zaadoptowane fonetycznie i zapisane pismem hebrajskim zapożyczenie $\mathrm{z}$ innego, bardzo podobnego dialektu, od wyrazu odziedziczonego. Po drugie niewiele łatwiejsza jest sytuacja w przypadku zapożyczeń, bo - jak widać na przykładzie nowowydanego słownika - trudno znaleźć we wschodnokaraimskim takie zapożyczenia, które pochodziłyby z języka mającego w przeszłości wpływ wyłącznie na dialekty zachodniokaraimskie ${ }^{10}$.

W tym miejscu należy wspomnieć jeszcze o transkrypcji niektórych źródeł w słowniku KRPS. We wstępie do Crimean Karaim-English dictionary (str. 10) czytamy, że dane językowe ze wspomnianego już wyżej rękopisu paryskiego zostały zaczerpnięte, z użyciem mylącej transkrypcji, bowiem znak wokalizacyjny patach, służący w zapisie wschodniokaraimskim dla oznaczenia samogłoski $a$ w każdej pozycji oraz $e$ w niepierwszej sylabie został odzwierciedlony w cyrylickiej transkrypcji literą $я$, co sugeruje lekcję ' $a$ - a więc odczyt przypominający fonetykę dialektu północno-zachodniego. Jednak jak pokazują dane

9 Na znaczące różnice między językiem mówionym a pisanym Karaimów krymskich zwracał uwagę już Radloff w swej relacji z podróży z 1888 roku, a ostatnio pisał o tym również Jankowski (2003a: 110).

10 Takimi językami są polski, białoruski oraz, w mniejszym stopniu, ukraiński, jednak nie znalazłem w słowniku Aqtay i Jankowskiego wyrazów, które mogłyby z tych języków pochodzić. W wykazie skróceń na str. 24 co prawda znajdziemy skrót „Pol. = Polish", jednak nie udało mi się w słowniku znaleźć wyrazu, który byłby według jego autorów pochodzenia polskiego (hasła w słowniku zawierają kwalifikatory etymologiczne). 
filologiczne oraz dyskusja dotycząca funkcji patachu w tekstach krymskich ${ }^{11}$, użycie tego znaku wokalizacyjnego w tych pozycjach raczej nie powinno być traktowane jako ślad wpływu północno-zachodniego w tym dialekcie - nawet jeśli zastanawiająca jest pewna zbieżność: patach, którego podstawową funkcją jest zapis samogłoski $a$ (oraz również ' $a$ w dialekcie północno-zachodnim), był, jak wspomniano, w dialekcie krymskim używany również do zapisu $e$ w niepierwszej sylabie ${ }^{12}$, a więc dokładnie w tej pozycji, w której w dialekcie północno-zachodnim w wieku XVII i XVIII doszło do zmiany $e>>^{\prime 13}$. Wiele wskazuje jednak na to, że zbieżność ta jest przypadkowa.

3. Sam słownik zawiera ok. 10 tys. haseł i uzupełniony został o suplement z wykazem imion i nazwisk krymskokaraimskich oraz z osobną listą hebrajskich imion, toponimów i etnonimów (pojawiających się przede wszystkim w przekładach Biblii) w lekcji wschodniokaraimskiej. Uzupełnienia te to novum, które na pierwszy rzut oka może się wydawać mało istotne, jednak jest to znaczący przyczynek do adaptacji hebrajskich nazw własnych na gruncie języka Karaimów krymskich.

O warsztacie leksykograficznym autorów już wspomnieliśmy wyżej, w tym miejscu pozostaje więc tylko poruszyć mniej istotną kwestię transkrypcji.

Korzystanie z materiału językowego zebranego w słowniku w pewnym stopniu utrudnia transkrypcja zastosowana przez autorów. Jest to system transkrypcyjny oparty na ortografii tureckiej, spójny i oczywiście znany już nauce. Wiemy, że w turkologii trudno o zunifikowaną transkrypcję, którą bylibyśmy w stanie objąć zapis wszystkich języków tej grupy (obojętnie czy chodzi o transkrypcję fonologiczną czy fonetyczną czy inną) $)^{14}$. Jednak transkrypcję użytą tu dla zapisu wschodniokaraimskiego jest trudniej pogodzić z zapisem dialektów zachodnich tego samego języka, niż z transkrypcją innych języków kipczackich, co jest już okolicznością skrajnie niekorzystną. Pominę tu różnice transkrypcyjne, które można z łatwością pogodzić i są raczej kwestią

11 Zob. artykuł Jankowskiego (1993) oraz pracę Józefa Sulimowicza (1972: 42, 45).

12 Oraz, oczywiście, również [a] w każdej pozycji w wyrazie.

13 Z całą pewnością rękopis paryski powstał na Krymie (por. charakterystyczne dla Krymu pismo półkursywne) a język jego nie może być zakwalifikowany jako północnokaraimski, zob. np. gendi gendini 'siebie na wzajem' (k. 84 ro), kiminin 'kogoś (genetivus)' (k. $85 \mathrm{r}^{\mathrm{o}}$ ). O chronologii północno-zachodniej zmiany $e>$ ' 'a zob. prace Németha (2014: 353-368; 2015a).

14 Więcej o tym można przeczytać w pracach Nikolaja Baskakowa $(1959,1968)$, czy Kamila Stachowskiego (2011). 
przyzwyczajenia. Największy problem sprawia zapis zachodniokaraimskiej (przede wszystkim południowo-zachodniej) głoski c. Jako że jest ona nieznana ani dialektowi wschodniokaraimskiemu, ani językowi tureckiemu, autorzy słownika - idąc za ortografią turecką - obciążyli literę $c$ wartością fonetyczną $\check{\zeta}(=$ pol. $\langle$ dż〉). Z powodu tej jednej niezgodności nie ma prostego rozwiązania na użycie w jednej i tej samej pracy wspólnej transkrypcji dla wszystkich trzech dialektów karaimskich; dane z dialektu wschodniokaraimskiego trzeba albo zapisywać w innej konwencji albo transponować na inną, kompatybilną z zapisem używanym dla zachodniokaraimskiego transkrypcję. Bardziej pożytecznym byłoby rozwiązanie oparte na innym szeroko rozpowszechnionym systemie transkrypcyjnym, używanym nie tylko w turkologii, ale również w slawistyce, mongolistyce czy uralistyce, gdzie szereg zębowych i dziąsłowych spółgłosek szczelinowych i zwarto-szczelinowych (palatalizowanych i niepalatalizowanych) jest zapisywany znakami $c, s, z, z-\dot{c}, \dot{s}, \dot{z}, \dot{z}-\check{c}, \check{s}, \check{z}, \check{z}-\check{c}, \check{s}, \check{z}, \check{z}^{15}$.

Niepotrzebnie osmańskocentryczne jest też użycie tureckiej litery $\breve{g}$, bowiem narzuca ona zbędne skojarzenia z turecką ortografią ${ }^{16}$, a przecież wiemy, że w dialekcie krymskim nie była ona wymawiana tak, jak w języku tureckim. Być może bardziej neutralnym i przez to nieco korzystniejszym byłoby użycie znaku $\dot{g}$ w tej roli.

4. Powróćmy jednak na chwilę jeszcze do kwestii lokalizacji języka karaimskiego na mapie języków turkijskich. W wielu dotychczasowych klasyfikacjach języków turkijskich wszystkie trzy dialekty karaimskie były przyporządkowywane do jednej i tej samej podgrupy (u różnych badaczy inaczej nazywanej - w zależności od kryteriów klasyfikacji). I tak na przykład u Aleksandra Samojlovicza (1922) jest to tzw. podgrupa tau (czyli kipczacka; chodzi o kryterium fonetyczne), którą później Tadeusz Kowalski (1926) a także Martti Räsänen (1953)

15 Nie wchodząc zbytnio w szczegóły, zaznaczmy, że jest oczywiście możliwość posłużenia się dla zapisu $c$ w dialekcie półudniowozachodnim znakami wziętymi z innych systemów transkrybowania. Można sięgnąć np. po znak $\mathfrak{t}$ z międzynarodowego alfabetu fonetycznego (IPA) lub po tym podobne. Takie mieszanie różnych konwencji byłoby jednak odejściem od systemu spójnego, czytelnego i przewidywalnego, a przecież to jest podstawową cechą dobrej transkrypcji. Notabene dla zrozumienia, jak bardzo IPA nie odpowiada potrzebom turkologów (i nie tylko), warto przeczytać poświęcony temu passus we wspomnianej wyżej pracy K. Stachowskiego (2011: 317-318).

16 Turecka litera $\breve{g}$ (tur. yumuşak ge) w otoczeniu samogłosek przedniojęzykowych jest wymawiana jak pol. j, zaś w otoczeniu samogłosek tylnojęzykowych lub środkowego a nie jest ona wymawiana - oznacza wówczas wzdłużenie samogłoski poprzedzającej. 
czy Kenesbaj Musaev (1966) nazywają grupą północno-zachodnią. Karl Heinrich Menges (1953) grupę północno-zachodnią dzieli na mniejsze jednostki i wydziela tzw. ponto-kaspijską podgrupę (Ponto-Caspian group) w której umieszcza karaimski bez wzmianek o jego dialektach. Podobnież czyni Johannes Benzing (1959) z tą różnicą, że grupę nadrzędną w stosunku do podgrupy ponto-kaspijskiej nazywa kipczacko-kumańską (Kipchak-Koman languages). U Baskakowa (1966) karaimski jest zaklasyfikowany do podgrupy kipczacko-oguzyjskiej języków kipczackich. W klasyfikacjach Talata Tekina (1991) i Árpáda Berty (1998) oraz w artykule Omeljana Pritsaka (1959) uwględniono tylko dialekty zachodniokaraimskie ${ }^{17}$. Klasyfikacja Clausa Schöniga (1997-1998) - mimo że jest najbardziej szczegółowa ze wszystkich dotychczasowych i przedstawiono w niej w nowatorski sposób stopień skomplikowania podziału współczesnych języków turkijskich, uwzględniając nie tylko cechy fonetyczne, ale równiez morfologiczne, składniowe czy, co w niej najistotniejsze, względy arealne - nie zawiera wzmianek o wschodniokaraimskim ${ }^{18}$. Podobnie rzecz się ma w klasyfikacji Larsa Johansona (1998).

Można więc powiedzieć, że miejscem dialektu wschodniokaraimskiego na mapie języków turkijskich zajmował się dotychczas de facto wyłącznie Henryk Jankowski, podejmując się również wstępną próby opisu jego poddialektów (2003b: 131-150). W jego klasyfikacji język Karaimów krymskich jest wyraźnie oddzielony od dialektów zachodniokaraimskich ${ }^{19}$. Dodajmy jeszcze, że w 2009 roku Gulayhan Aqtay opublikowała obszerną edycję bardzo ważnych źródeł języka krymskokaraimskiego, w której zwraca ona szczególną uwagę na trudności związane z ustaleniem przynależności językowej niektórych tekstów. W świetle powyższego należy stwierdzić, że autorzy nowopowstałego słownika zrobili dotychczas bodaj najwięcej w sprawie badań na statusem języka krymskokaraimskiego, a ich nowe dzieło wpisuje się w profil ich rzetelnej, opartej na badaniach filologicznych pracy.

17 Berta pisał tylko o współczesnych językach turkijskich.

18 Schönig, podobnie jak Berta, zajął się wyłącznie żywymi językami (choć nie odrywa ich całkowicie od historycznego tła) i dlatego wschodniokaraimski został pominięty w jego cyklu artykułów.

19 Język karaimski oraz języki najbardziej do niego zbliżone Jankowski porządkuje, dzieląc je na trzy grupy: zachodniokaraimski tworzy osobną grupę ze swymi dwoma dialektami, w skład tzw. kaukaskiej grupy wchodzą kumycki i karaczajsko-bałkarski, natomiast częścią krymskiej grupy są kipczackie dialekty krymskotatarskiego, kipczackie dialekty urumskiego, krymskokaraimski (wymarły) oraz krymczacki (wymarły). 


\section{Bibliografia}

Aqtay, Gulayhan, Eliyahu ben Yosef Qllcis anthology of Crimean Karaim and Turkish literature. Critical edition with introduction, indexes and facsimile, Y1ldiz Dil ve Edebiyat Dizisi, nr 8, t. 1-2, İstanbul 2009.

Aqtay, Gulayhan, Jankowski, Henryk, A Crimean Karaim-English dictionary, Prace Karaimoznawcze, nr 2, Poznań 2015.

Baskakov, Nikolaj Aleksandrovič, O proekte jedinoj fonetičeskoj transkripcii dlja tjurkskich jazykov, Moskva 1959.

Baskakov, Nikolaj Aleksandrovič, Tjurkskie jazyki (obščie svedenija i tipologičeskaja charakteristika), [w:] Jazyki narodov SSSR. Tom vtoroj: Tjurkskie jazyki, red. N. A. Baskakov $\mathrm{i}$ in., Moskva 1966, s. 7-42.

Baskakov, Nikolaj Aleksandrovič, Türk Dilleri Genel Fonetik Transkripsiyonu Üzerine, [w:] XI. Türk Dil Kurultaynda Okunan Bilimsel Bildiriler, zespół redakcyjny nie podany, Ankara 1968, s. 53-59.

Baskakov, N. A., Šapšal, S. M., Zajončkovskij, A. (red.), Karaimsko-russko-poĺskij slovaŕ. Slownik karaimsko-rosyjsko-polski, Moskva 1974.

Benzing, Johannes, Classification of the Turkic languages, [w:] Philologiae Turcicae Fundamenta, t. 1, red. L. Bazin, A. Bombacı, J. Deny, T. Gökbilgin, F. İz, H. Scheel, Wiesbaden 1959, s. 1-5.

Berta, Árpád, West Kipchak Languages, [w:] The Turkic Languages, red. L. Johanson, É. Á. Csató, London, New York 1998, s. 301-317.

Chafuz, Mark Ėzrovič, Russko-karaimskij slovaŕ. Krymskij dialekt, Moskva 1995.

Çulha, Tülay, Karaycamın Kısa Sözvarhğı. Karayca-Türkçe Kısa Sözlük, Dil ve Edebiyat Dizisi, nr 6, İstanbul 2006.

Dubiński, Aleksander, Batı Karaim dilinde bazı leksik farklar, [w:] XI. Türk Dil Kurultayında Okunan Bilimsel Bildiriler, zespół redakcyjny nie podany, Ankara 1968.

Dubiński, Aleksander, Lokalizacja języka karaimskiego w świetle jego rozwoju historycznego, „Przeglad Orientalistyczny” 1993, nr 165-166, s. 37-42 [przedruk w: Dubiński, Aleksander, Caraimica. Prace karaimoznawcze, red. T. Majda, Warszawa 1994, s. 113-120].

Jankowski, Henryk, Jak Krymscy Karaimowie czytaja patah i co z tego wynika?, [w:] Studia Orientalia Thaddeo Lewicki oblata. Materialy sesji naukowej poswięconej pamięci Profesora Tadeusza Lewickiego, Kraków 17-18 listopada 1993, red. E. Górska, B. Ostafin, Kraków 1993, s. 107-114.

Jankowski, Henryk, A Bible translation into the northern Crimean dialect of Karaim, „Studia Orientalia” 1997, nr 82, s. 1-82.

Jankowski 2003a = Jankowski, Henryk, On the language varieties of Karaims in the Crimea, „Studia Orientalia” 2003, nr 95, s. 109-130.

Jankowski 2003b = Jankowski, Henryk, Position of Karaim among the Turkic Languages, „Studia Orientalia” 2003, nr 95, s. 131-150.

Jankowski, Henryk, The question of the existence of the Crimean Karaim and its relation to western Karaim, [w:] Orientas Lietuvos Didžiosios Kunigaikštijos visuomenés tradicijoje: 
totoriai ir karaimai (= Straipsniu rinkinys, parengtas pranešimu, skaitytu tarptautineje mokslo konferencijoje "610-osios totoriu ir karaimu isikūrimo Lietuvos Didžiojoje Kunigaikštijoje metinès" 2007 m. rugsèjo 13-15 d. Vilniaus universitete, pagrindu), red. T. Bairašauskaitè, H. Kobeckaitè, G. Miškinienė, Vilnius 2008, s. 162-168.

Jankowski, Henryk, Translations of the Bible into Karaim, „Religion Compass” 2009, nr 3/4, s. 502-523.

Jankowski, Henryk, Wkład Hadży Seraji Szapszała do turkologii: tryb złożyczacy i udział $w$ Słowniku karaimsko-rosyjsko-polskim, „Almanach Karaimski” 2014, nr 3, s. 49-58. Jankowski, Henryk, Crimean Turkish Karaim and the old north-western Turkic tradition of the Karaites, „Acta Orientalia Academiae Scientiarum Hungaricae” 2015, nr 68, z. 2, s. 199-214.

Johanson, Lars, The history of Turkic, [w:] The Turkic languages, red. L. Johanson, É.Á. Csató, London, New York 1998.

Józefowicz, Gabriel, Słownik polsko-karaimski w dialekcie trockim, Trakai, Vilnius, Warszawa, Wrocław, Gdańsk, Nashville 2008.

Juchniewicz, Szymon, Podreczny słownik polsko-karaimski, [Warszawa] 2008.

Kowalski, Tadeusz, Jezyk karaimski, „Myśl Karaimska” 1926, nr 2, z. 3, s. 3-7.

Kowalski, Tadeusz, Karaimische Texte im Dialekt von Troki, Prace Komisji Orjentalistycznej Polskiej Akademji Umiejętności, nr 11, Kraków 1929.

Lavrinovič, Mark, Russko-karaimskij slovaŕ, Trakai 2007.

Lavrinovičius, Markas, Russko-karaimskij slovaŕ. Urus-karaj sioźliugiu, Trakai 2012.

Levi, Boris Zacharovič, Russko-karaimskij slovaŕ(krymskij dialekt). Urus-qaraj sözlük, Simferopol 2005 [pierwsze wydanie: 1996].

Menges, Karl Heinrich, Classification of the Turkic languages, [w:] Philologiae Turcicae Fundamenta, t. 1, red. L. Bazin, A. Bombac1, J. Deny, T. Gökbilgin, F. İz, H. Scheel, Wiesbaden 1953, s. 5-10.

Musaev, Kenesbaj Musaevič, Karaimskij jazyk, [w:] Jazyki narodov SSSR. Tom vtoroj: Tjurkskie jazyki, red. N. A. Baskakov i in., Moskva 1966, s. 260-279.

Németh, Michal, A historical phonology of Western Karaim: The evolution of consonant harmony in the north-western dialect, „Studia Linguistica Universitatis Iagellonicae Cracoviensis" 2014, nr 131, z. 4, s. 353-368.

Németh 2015a = Németh, Michał, A historical phonology of Western Karaim. The process of its diversification into dialects, „Studia Linguistica Universitatis Iagiellonicae Cracoviensis” 2015, nr. 132, z. 3, s. 167-185.

Németh 2015b = Németh, Michał, An early North-Western Karaim Bible translation from 1720. Part 3. A contribution to the question of the stemma codicum of the Eupatorian print from 1841, „Karaite Archives” 2015, nr 2, s. 103-118.

Pritsak, Omeljan, Das Karaimische. [w:] Philologiae Turcicae Fundamenta, t. 1, red. L. Bazin, A. Bombac1, J. Deny, T. Gökbilgin, F. İz, H. Scheel, Wiesbaden 1959, s. 318-340.

Radloff, Wilhelm [= Radlov, Vasilij Vasilevič], Opyt slovarja tjurkskich narečij. Versuch eines Wörterbuches der Türk-Dialekte, t. 1-4, Sanktpeterburg" 1893-1911. 
Radloff, Wilhelm, Bericht über eine Reise zu den Karaimen der westlichen Gouvernements, „Bulletin de l'Académie Impériale des Sciences de St-Pétersbourg" 1888, nr 32, s. 173-182.

Räsänen, Martti, Contributions au classement des langues turques, „Rocznik Orientalistyczny" 1953, nr 17, s. 92-104.

Schönig, Claus, A new attempt to classify the Turkic languages (1, 2, 3), „Turkic Languages” 1997, nr 1, s. 117-133, 262-277; 1998, nr 2, s. 130-151.

Shapira, Dan, The Turkic languages and literatures of the East European Karaites, [w:] Karaite Judaism. A guide to its history and literary sources, red. M. Polliack, Leiden, Boston 2003, s. 657-728.

Shapira, Dan, The Karaim translation of the Book of Nehemia copied in the $17^{\text {th }}$ century's Crimea and printed in 1840/1841 at Gözleve, on the copyist of the manuscript, and some related issues, „Karaite Archives” 2013, nr 1, s. 133-198.

Samojlovič, Aleksandr Nikolaevič, Nekotorye dopolnenija k klassifikacii tureckich jazykov, Sanktpeterburg" 1922.

Sinani, Zacharij Osipovič, Kratkij slovaŕ razgovornogo jazyka krymskich karaimov [rukopiś], Simferopoí 1970.

Sinani, Zacharij Osipovič, Karaimsko-russkij i russko-karaimskij slovaŕ razgovornogo jazyka. Simferopoĺ 2007.

Stachowski, Kamil, Remarks on the usefulness of different types of transcription, with a particular regard to Turkic comparative studies, „Suomalais-Ugrilaisen Seuran Aikakauskirja / Journal de la Société Finno-Ougrienne” 2011, nr 93, s. 303-338.

Sulimowicz, Józef, Materiał leksykalny krymskokaraimskiego zabytku jezykowego (druk $z 1734$ r.), „Rocznik Orientalistyczny” 1972, nr 35, z. 1, s. 37-76.

Tekin, Talat, A New Classification of the Turkic Languages, „Türk Dilleri Araştırmaları” 1991, [tom bez numeru], s. 5-18.

Walfish, Barry Dov (we współpracy z: Kizilov, Mikhail), Bibliographia Karaitica. An annotated bibliography of Karaites and Karaism, Leiden, Boston 2011. 
